\title{
Crescimento econômico e desenvolvimento: uma avaliação dos indicadores para os municípios do Corede Médio Alto Uruguai - Codemau
}

\author{
Tamara Silvana Menuzzi Diverio \\ Universidade Regional Integrada do Alto Uruguai e das Missões \\ Luiz Gustavo Zuliani da Silva \\ Universidade Regional Integrada do Alto Uruguai e das Missões
}

\begin{abstract}
Resumo
A atividade agrícola é um dos propulsores da economia dos municípios que compõem o Corede Médio Alto Uruguai - Codemau. A partir de 2012 a indústria passou a ocupar lugar de destaque, isso se deve principalmente à implantação da Barragem Foz do Chapecó, no Município de Alpestre. Assim, este artigo procura apresentar e discutir os indicadores do crescimento econômico e do desenvolvimento nos municípios que compõem este Conselho Regional de Desenvolvimento - Corede. Busca-se avaliar o desenvolvimento não apenas do ponto de vista do crescimento econômico, mas, também pelo prisma de outras dimensões capazes de interpretar a realidade humana. Neste sentido, trabalha-se neste estudo com o Índice de Desenvolvimento Humano municipal - IDH-M, Índice de Desenvolvimento Sócio Econômico - Idese, Produto Interno Bruto - PIB e Índice de Gini. Como resultado final aponta-se que houve redução da desigualdade na maioria dos municípios do Codemau, com exceção dos municípios de Ametista do Sul, Pinheirinho do Vale e Vista Alegre que apresentaram aumento da desigualdade no período de 2000 a 2010. A região é considerada uma das regiões do Estado com baixo PIB e Idese, tendo grandes problemas e gargalos, enfrentando dificuldade quanto a investimentos que venham a gerar novos postos de trabalho e renda.
\end{abstract}

Palavras-Chave: Crescimento. Desenvolvimento. Médio Alto Uruguai.

Economic growth and development: an evaluation of the indicators for the municipalities of Corede Medium High Uruguay - Codemau

\footnotetext{
Abstract

The agricultural activity is one of propellants of the economy of the cities that compose the CODEMAU, from 2012 the industry started to occupy prominence place, this if it mainly must to the implantation of the Barrage Estuary of the Chapecó, in the city of Alpestre. Thus, this article looks for to present and to argue the pointers of the economic growth and
} 
the development in the cities that compose this Corede. One searches to not only evaluate the development of the point of view of the economic growth, but, also for the prism of other dimensions capable to interpret the reality human being. In this direction, one works in this study with the Municipal Human Development Index (MHDI), Socioeconomic Development Index (IDESE), Gross domestic product (GDP) and Gini coefficient. As final result is pointed out that it had reduction of the inequality in the majority of the cities of the CODEMAU, with exception of the Amethyst cities of the South, Pinheirinho of the Valley and Glad Sight that had presented increase of the inequality in the period of 2000 the 2010. The region is considered one of the regions of the State with the low GIP and IDESE, having had great problems and bottlenecks, facing difficulty how much the investments that come to generate new ranks of work and income.

Keywords: Growth. Development. Middle High Uruguay.

\section{Crecimiento económico y desarrollo: una evaluación de los indicadores para las autoridades locales de Corede Medio Uruguay Alto - Codemau}

\section{Resumen}

La actividad agrícola es uno de los propulsores de la economía de las ciudades que componen el CODEMAU, a partir del 2012 la industria comenzada para ocupar el lugar de la distinción, este sí debe principalmente a la implantación del estuario de la presa del Chapecó, en la ciudad de Alpestre. Así, este artículo trata de presentar y hablar de los indicadores del crecimiento económico y del desarrollo en las ciudades que componen este Corede. Se mira para valorar el desarrollo del punto de vista del crecimiento económico, pero, también para el prisma de otras dimensiones capaces de interpretar la realidad humana. En este sentido, allí se trabaja en este estudio con el índice del desarrollo humano municipal (IDH-M), el índice del desarrollo socio Económico (IDESE), Producto nacional bruto (PNB) y índice de Gini. Ya que el resultado final indica que había reducción de la desigualdad en la mayor parte de las ciudades del CODEMAU, con la excepción de las ciudades de Ametista do Sul, Pinheirinho del Valle y Vista Alegre que habían presentado a aumento de la desigualdad en el período de 2000 hasta 2010. La región se considera una de las regiones del estado con bajo PNB e IDESE, teniendo grandes problemas y cuellos de botella, estando enfrente de la dificultad en cuanto a inversiones que vienen para producir nuevos puestos de trabajo e ingresos.

Palabras clave: Crecimiento. Desarrollo. Medio Alto Uruguay.

\section{INTRODUÇÃO}

O processo de globalização das últimas décadas tem acelerado a reconfiguração espacial das atividades econômicas, modificando e tornando mais dinâmicas algumas regiões do planeta, enquanto outras ficam destinadas à estagnação e ao declínio. Por globalização, entende-se a existência de valores locais alicerçados em ambientes competitivos em escala planetária que estimulam relações em dimensões intercontinentais, fazendo com que sistemas locais se subordinem aos sistemas globais.

No século $X X$, intensificaram-se as modificações técnicas científicas informacionais e as redes de informações difundem-se por todo mundo sempre de forma desigual. A modernização a qualquer preço ultrapassa o domínio do industrial impondo-se ao setor público e invade áreas como a manipulação da mídia, o conteúdo do ensino em todos os graus, a vida religiosa, a profissionalização e as 
relações de trabalho. Observa-se que este processo é rápido e resulta em um crescimento econômico onde o capital comanda o território e o trabalho. Santos e Silveira (2001) salientam: "de um tempo lento, diferenciado segundo as regiões passamos para um tempo rápido, um tempo hegemônico único, influenciado pelo dado internacional: os tempos dos Estados e das multinacionais".

Sendo assim, o capital financeiro desregulado e as grandes empresas internacionais procuram se localizar e relocalizar conforme condições mais ou menos favoráveis à geração de lucros. Por outro lado, governos nacionais e locais perderam controle sobre o próprio desenvolvimento. Os governos, desde o pósguerra, têm buscado atenuar as desigualdades regionais com políticas compensatórias de desenvolvimento. Essas políticas visavam à atração de capitais produtivos para as regiões menos desenvolvidas, por meio de incentivos fiscais, crédito barato e investimento público em infraestrutura conveniente às empresas. No entanto, os resultados não foram os esperados, pois além de não se observar o esperado dinamismo econômico, houve aumento da concentração de renda e deterioração na qualidade de vida das populações.

De acordo com Santos (2000), a globalização revaloriza os lugares e estes, de acordo com o que podem oferecer às empresas, fortalecem a globalização na forma em que se apresenta, favorecendo a competitividade. Entre o território e a globalização, cria-se uma relação de causalidade em benefício dos atores mais poderosos, dando ao espaço geográfico um papel incomum na dinâmica local. No que se refere à relação entre globalização e território, o autor salienta que a globalização amplia o conceito de território, devido à competitividade, a busca difícil pela maior produtividade depende de condições oferecidas nos lugares da produção, nos lugares da circulação, nos lugares do consumo. Quer dizer, há lugares mais apropriados para aumentar o lucro de alguns em detrimento de outros. Para Santos (2000, p. 65) "A globalização mata a noção de solidariedade, devolve o homem à condição primitiva do cada um por si, e como se voltássemos a ser animais da selva, reduz as noções de moralidade pública e particular a um quase nada". Sendo assim, o autor coloca que "uma outra globalização supõe uma mudança radical das condições atuais, de modo que a centralidade de todas as ações seja localizada no homem [...]" e não mais no dinheiro (SANTOS, 2000, p.146).

Dupas (2006) acrescenta ainda que utilizar sofisticada tecnologia e logística de ponta, para vender em grande escala e a preços menores a uma população com renda cada vez mais baixa, empregando pessoal muito mal remunerado, é um dos principais fatores da alta taxa de acumulação de muitos setores do capitalismo global. Sublinhando isso, no modelo de globalização surgem novos paradigmas, além da minimização da importância do Estado, que vem sendo, muitas vezes, questionado sobre o seu papel em relação às questões sociais. Nesse contexto, fortalece-se a ideia de desenvolvimento, que, conforme Boisier (2006), encontra-se numa fase de transição entre a antiga concepção, que o assimilava à ideia de crescimento econômico, e uma nova ideia associada mais com atitudes e menos com conquistas materiais.

Cabe destacar que, por muito tempo, o desenvolvimento era medido basicamente pelo PIB, ou seja, a soma de tudo o que foi produzido em um país por ano. Economistas, estudiosos do assunto, concluíram que apenas essa análise era incompleta, pois ignorava a dimensão humana da atividade econômica. Além de 
limitar ao resultado da produção o cálculo do avanço de um país. O PIB também não leva em conta se a riqueza está concentrada nas mãos da população com maior renda. Delevati (2001) observa que, mesmo em países que apresentaram altas taxas de crescimento econômico, as condições de vida das populações não melhoraram e, em alguns casos, até pioraram, aumentando simultaneamente a pobreza e as desigualdades em vez de reduzi-las.

Furtado (1974, p. 94) acrescenta ainda: "a elevação da taxa de crescimento tende a acarretar agravação tanto da dependência externa como da exploração interna. Assim, taxas mais altas de crescimento, longe de reduzir o subdesenvolvimento, tendem a agravá-lo, no sentido de que tendem a aumentar as desigualdades sociais". O referido autor observa o modelo atual, que, além de destruir e degradar o meio ambiente, cria a ideia de que quanto maior for $o$ crescimento do PIB, maior será o desenvolvimento.

Sen (2005) reforça destacando que não se julga o sucesso de uma sociedade em termos de seu PIB, pois é preciso ver a liberdade em diferentes perspectivas, e a totalidade disso, o aprimoramento, é desenvolvimento. Dupas (2006, p. 154) observa que "setores não rentáveis como educação, saúde e serviços sociais vêm se reduzindo; enquanto isso, segurança privada e conflitos bélicos são indústrias em pujante crescimento".

Furtado (1974, 68-69) vê o desenvolvimento como um mito, pois, "o processo de acumulação tende a ampliar o fosso entre um centro, em crescente homogeneização, e uma constelação de economias periféricas [nas quais se denota] um distanciamento das formas de vida de uma minoria privilegiada com respeito à massa da população". Muitos estudiosos destacam que o objetivo do desenvolvimento é alargar as possibilidades de escolha das pessoas, através da ampliação de suas capacidades e do âmbito das suas atividades. Por isso, o desenvolvimento não pode ser reduzido a apenas à performance econômica dos países. Sendo assim, o PIB per capita não é uma medida do desenvolvimento.

Como seria possível medir o desenvolvimento de uma região ou um país sem utilizar o PIB per capita? Isso se tornou mais próximo do possível quando se estabeleceu uma metodologia que permite avaliar o desenvolvimento não apenas do ponto de vista do crescimento econômico, mas também pelo prisma de outras dimensões capazes de interpretar a realidade humana, como a longevidade e o nível educacional, isto é, do IDH. O objetivo da elaboração do IDH é oferecer um contraponto ao PIB per capita, que considera apenas a dimensão econômica do desenvolvimento. Criado por Mahbud ul Haq, com a colaboração do economista indiano Amartya Sen, o IDH pretende ser uma medida geral, sintética, do desenvolvimento humano. Ou seja, o IDH é um índice que mede a qualidade de vida em países ou regiões. Para a Organização das Nações Unidas - ONU, o bem-estar de uma população está ligado a uma alta expectativa de vida, jovens matriculados na escola, adultos alfabetizados e boa renda per capita.

Ressalta-se que o diagnóstico indicador do crescimento econômico e do desenvolvimento dos municípios desta região, em grande parte dependente da agricultura, que, até 2010, era a principal atividade econômica regional, apresenta uma inversão a partir de 2012 e a indústria passa a ocupar a primeira posição. Neste contexto, este trabalho busca apresentar e discutir os indicadores do crescimento econômico e do desenvolvimento nos municípios que compõem o Codemau. 


\section{METODOLOGIA}

Utiliza-se como universo de estudo a região do Médio Alto Uruguai, sendo o recorte espacial utilizado o Codemau, que abrange os seguintes municípios: Alpestre, Ametista do Sul, Caiçara, Cristal do Sul, Dois Irmãos das Missões, Erval Seco, Frederico Westphalen, Gramado dos Loureiros, Iraí, Nonoai, Novo Tiradentes, Palmitinho, Pinhal, Pinheirinho do Vale, Planalto, Rio dos Índios, Rodeio Bonito, Seberi, Taquaruçu do Sul, Trindade do Sul, Vicente Dutra, Vista Alegre (Figura 1).

Figura 1. Mapa de localização dos Coredes no estado do Rio Grande do Sul, com destaque aos municípios que formam o Codemau

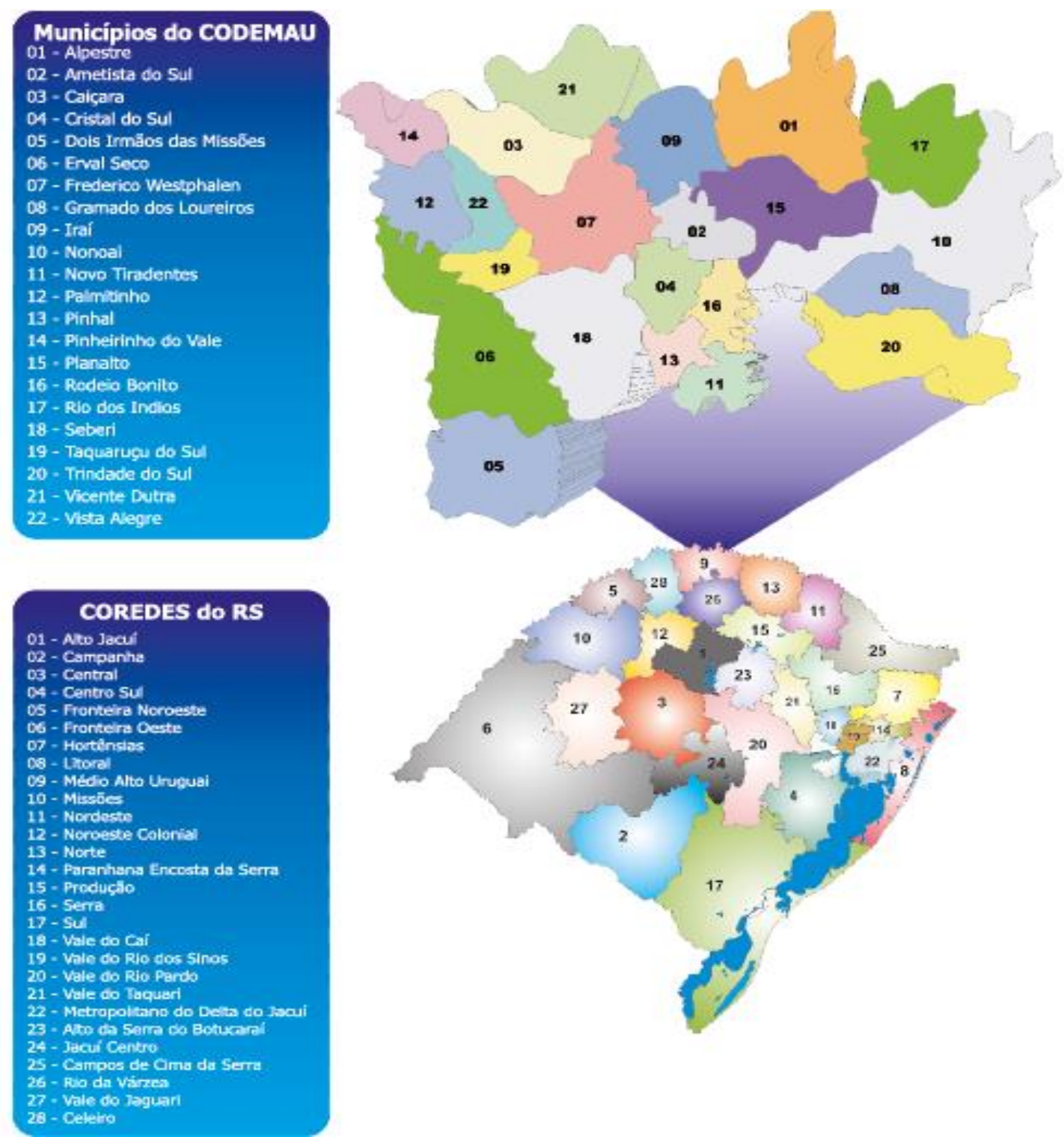

Fonte: Plano estratégico do Codemau 2014/2015.

Siedenberg (2006, p.53) coloca que Coredes são fóruns regionais de discussão e decisão sobre estratégias, políticas e ações que visem o 
desenvolvimento regional, constituídos como pessoas jurídicas de direito privado, organizados sob a forma de associações civis sem fins lucrativos.

O Codemau é um dos 28 Coredes do estado do Rio Grande do Sul, criados pela Lei Estadual $n^{\circ} 10.283$ de 17/10/1994 e regulamentados pelo Decreto $n^{\circ} 35.764$, de 28/12/1994, cuja missão é ser espaço plural e aberto de construção de parcerias sociais e econômicas, em nível regional, por meio da articulação política dos interesses locais e setoriais em torno de estratégias próprias e específicas de desenvolvimento para as regiões do Rio Grande do Sul.

Dados da Fundação de Economia e Estatística - FEE (2015) apontam que a região do Médio Alto Uruguai apresentou, no ano de 2014, população total de 148.476 habitantes nos 22 municípios que compõe o Corede, possui área de 4.200,3 $\mathrm{km}^{2}$ e densidade de 35,35 hab/km². Em 2010, a taxa de analfabetismo de pessoas com 15 anos ou mais foi de 9,42\%. A expectativa de vida ao nascer é de 71,25 anos. Já em 2013, o coeficiente de mortalidade infantil registrou 11,62 por mil nascidos vivos, com PIB per capita de R\$16.494,00 e Exportações Totais em 2014 de U\$ FOB 49.381.302,00.

Para entender as principais variáveis analisadas nesse trabalho (IDH, IDESE, Índice de Gini e PIB) optou-se também por apresentar dados referentes à População (urbana e rural); Taxa de Urbanização e Densidade Demográfica; Razão de Dependência (RD); Taxa de Escolaridade e Analfabetismo; e Distribuição da economia por segmento, a fim de compreender aspectos relevantes que compõe os principais indicadores e caracterizar melhor a região de estudo.

Para avaliar as desigualdades sociais, utilizou-se o Índice de IDH-M. O IDH, de acordo com Programa das Nações Unidas para o Desenvolvimento - PNUD, é obtido pela média aritmética simples de três subíndices, referentes à Longevidade (IDHLongevidade), Educação (IDH-Educação) e Renda (IDH-Renda). Utilizaram-se valores de IDH-M de 2000 e 2010. Calcularam-se os percentuais de variação para verificar a evolução por municípios em uma década. Ressaltaram-se os maiores e menores valores de IDH dos municípios do Codemau em relação ao IDH do Estado do Rio Grande do Sul.

Ressalta-se que cada país ou região recebe uma pontuação do IDH que varia entre o e 1. Os países são divididos em três faixas de IDH: 0,499 ou menos apresentam desenvolvimento humano baixo; de 0,500 a 0,799, desenvolvimento humano médio; e 0,800 para cima, alto. Então, quanto mais próximo de 1, maior será o nível de desenvolvimento humano do país ou região.

O IDESE foi analisado a partir de dados da FEE para o período entre 2007 e 2012. Para o PIB utilizou-se valores do PIB, per capita de 2012 dos municípios do Codemau. Utilizou-se ainda o Índice de Gini, valores de 2000 e 2010 para verificar as desigualdades econômicas dos municípios que compõem os municípios do Corede Médio Alto Uruguai. O Coeficiente de Gini mede o grau de desigualdade e seu valor varia de 0 a 1. Zero quando não há desigualdade, ou seja, quando a renda de todos os indivíduos tem o mesmo valor e 1 quando a desigualdade é considerada máxima.

A coleta de dados se deu por meio de fontes secundárias que foram oriundas de diversas fontes, entre elas: Atlas do Desenvolvimento Humano, IPEADATA, IBGE, FEE/FEE-DADOS e dados do Censo Demográfico. Destaca-se que os censos populacionais compõem uma fonte especial de dados sobre a condição de vida da população nos municípios e localidades. As realidades locais, rurais ou urbanas, 
dependem dos censos para serem avaliadas. Com periodicidade decenal, o Censo Demográfico tende a seguir o crescimento, a distribuição geográfica e a evolução de diferentes características da população ao longo do tempo. Na sequência, apresenta-se a análise e discussão dos resultados.

\section{ANÁLISE E DISCUSSÃO DOS RESULTADOS}

\subsection{População urbana e rural}

Com base nos dados disponibilizados pelos Censos/IBGE, 2000 e 2010, apresentados no Quadro 1, constata-se que a região do Médio Alto Uruguai perdeu 4,97\% de sua população no período, ou seja, de 156.163 habitantes em 2000, baixou para 148.403 habitantes em 2010. Cabe, no entanto, ressaltar que o período de maior intensidade migratória ocorreu entre os anos 1970 até o final dos anos 1990. Os dados apresentados na tabela 1 com a estimativa populacional divulgada pelo IBGE para 2015, demonstrou crescimento de 2,13\% na população, passando a 151.557 habitantes nos 22 municípios do Codemau, com aumento de 3.154 habitantes.

Tabela 1. População: Total, Urbana, Rural (Censo 2000/2010) e Estimativa populacional 2015

\begin{tabular}{|c|c|c|c|c|c|c|c|}
\hline \multirow{2}{*}{ 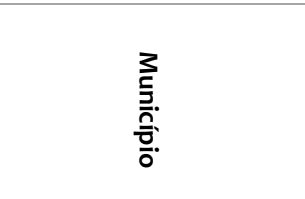 } & \multicolumn{3}{|c|}{ População 2000} & \multicolumn{3}{|c|}{ População 2010} & \multirow[t]{2}{*}{$\begin{array}{l}\text { Estimativa } \\
\text { IBGE } 2015\end{array}$} \\
\hline & $\begin{array}{l}-1 \\
\stackrel{+}{D} \\
\underline{D}\end{array}$ & 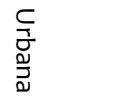 & 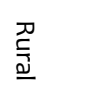 & $\begin{array}{l}-1 \\
\stackrel{0}{\underline{I}} \\
\underline{-}\end{array}$ & 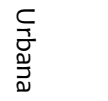 & 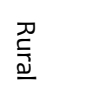 & \\
\hline Alpestre & 10.266 & 2.157 & 8.109 & 8.027 & 2.211 & 5.816 & 7.640 \\
\hline Ametista do Sul & 7.414 & 3.195 & 4.219 & 7.323 & 3.811 & 3.512 & 7.569 \\
\hline Caiçara & 5.580 & 1.489 & 4.091 & 5.071 & 1.594 & 3.477 & 5.104 \\
\hline Cristal do Sul & 2.874 & 444 & 2.430 & 2.826 & 931 & 1.895 & 2.917 \\
\hline Dois Irmãos das Missões & 2.365 & 933 & 1.432 & 2.157 & 1.094 & 1.063 & 2.174 \\
\hline Erval Seco & 9.177 & 3.246 & 5.931 & 7.878 & 3.437 & 4.441 & 7.773 \\
\hline Frederico Westphalen & 26.759 & 20.433 & 6.326 & 28.843 & 23.333 & $5 \cdot 510$ & 30.558 \\
\hline Gramado dos Loureiros & 2.543 & 426 & 2.117 & 2.269 & 526 & 1.743 & 2.270 \\
\hline Iraí & 9.250 & 5.590 & 3.660 & 8.078 & 4.457 & 3.621 & 8.020 \\
\hline Nonoai & 12.822 & 8.794 & 4.028 & 12.074 & 9.067 & 3.007 & 12.295 \\
\hline Novo Tiradentes & 2.412 & 564 & 1.848 & 2.277 & 654 & 1.623 & 2.320 \\
\hline Palmitinho & 6.943 & 2.577 & 4.366 & 6.920 & 3.393 & 3.527 & 7.170 \\
\hline Pinhal & 2.503 & 977 & 1.526 & 2.513 & 1.290 & 1.223 & 2.609 \\
\hline Pinheirinho do Vale & 4.184 & 677 & 3.507 & 4.497 & 915 & 3.582 & 4.761 \\
\hline Planalto & 11.302 & 5.757 & 5.545 & 10.524 & 5.932 & 4.592 & 10.678 \\
\hline Rio dos Índios & 4.702 & 597 & 4.105 & 3.616 & 755 & 2.861 & 3.418 \\
\hline Rodeio Bonito & 5.751 & 3.899 & 1.852 & 5.743 & $4 \cdot 310$ & 1.433 & 5.955 \\
\hline Seberi & 11.349 & 5.432 & 5.917 & 10.897 & 5.923 & 4.974 & 11.164 \\
\hline Taquaruçu do Sul & 2.921 & 928 & 1.993 & 2.966 & 1.164 & 1.802 & 3.090 \\
\hline Trindade do Sul & 5.922 & 2.141 & 3.781 & 5.787 & 2.899 & 2.888 & 5.961 \\
\hline Vicente Dutra & 6.128 & 2.307 & 3.821 & 5.285 & 2.351 & 2.934 & 5.224 \\
\hline Vista Alegre & 2.996 & 1.023 & 1.973 & 2.832 & 1.185 & 1.647 & 2.887 \\
\hline Total & 156.163 & 73.586 & 82.577 & 148.403 & 81.232 & 67.171 & 151.557 \\
\hline
\end{tabular}

Fonte: IBGE - Censo Demográfico 2000 e 2010 e Estimativa do IBGE 2015. 
Incentivos governamentais direcionados à produção em escala, com o propósito de exportação de grãos, aliado à falta de oportunidade de trabalho em outros segmentos produtivos para os jovens, principal força de trabalho, estimulou a imigração destes para outras regiões do Estado e País, em busca de novas oportunidades, resultando no empobrecimento da agricultura familiar.

A partir de 2000, o ritmo começa a se estabilizar. A saída de pessoas da região comparando a anos anteriores é bem menor. A articulação e a mobilização das Instituições Públicas e Privadas locais integradas à comunidade tomaram decisões arrojadas para reverter a situação, e os resultados começam a dar sinal de melhora. Um novo modelo de desenvolvimento sustentável vem sendo construído, criando condições para que a população permaneça na região vivendo com qualidade de vida.

\subsection{Taxa de urbanização e densidade demográfica}

O crescimento populacional do período resultou em densidades populacionais mais altas em alguns municípios do Codemau, conforme apresentado na Tabela 2. Frederico Westphalen é o único município com densidade superior a $100 \mathrm{hab} / \mathrm{km}^{2}$. Há que se observar que a densidade levantada é a do município como um todo, sem discriminação de áreas rurais, o que favorece municípios com maior proporção de áreas urbanas, caso de Frederico Westphalen. Com mais de 50 $\mathrm{hab} / \mathrm{km}^{2}$ aparecem apenas três dos 22 municípios pesquisados. Além de Frederico Westphalen, já mencionado, os municípios de Ametista do Sul e Rodeio Bonito possuem densidades demográficas de 78,33 e 69,03 hab/km², respectivamente.

Tabela 2. Taxa de Urbanização e Densidade Demográfica - 2010

\begin{tabular}{|c|c|c|}
\hline Local & $\begin{array}{l}\text { Taxa de Urbanização } \\
(\%)\end{array}$ & $\begin{array}{c}\text { Densidade Demográfica } \\
\text { hab./km² }\end{array}$ \\
\hline Alpestre & 27,54 & 24,73 \\
\hline Ametista do Sul & 52,04 & 78,33 \\
\hline Caiçara & 31,43 & 26,80 \\
\hline Cristal do Sul & 32,94 & 28,92 \\
\hline Dois Irmãos das Missões & 50,72 & 9,56 \\
\hline Erval Seco & 43,63 & 21,65 \\
\hline Frederico Westphalen & 80,90 & 108,85 \\
\hline Gramado dos Loureiros & 23,18 & 17,27 \\
\hline Iraí & 55,17 & 44,64 \\
\hline Nonoai & 75,10 & 25,75 \\
\hline Novo Tiradentes & 28,72 & 30,20 \\
\hline Palmitinho & 49,03 & 48,04 \\
\hline Pinhal & 51,33 & 36,84 \\
\hline Pinheirinho do Vale & 20,35 & 42,58 \\
\hline Planalto & 56,37 & 45,67 \\
\hline Rio dos Índios & 20,88 & 15,37 \\
\hline Rodeio Bonito & 75,05 & 69,03 \\
\hline Seberi & 54,35 & 36,15 \\
\hline Taquaruçu do Sul & 39,24 & 38,60 \\
\hline Trindade do Sul & 50,10 & 21,56 \\
\hline Vicente Dutra & 44,48 & 27,38 \\
\hline Vista Alegre & 41,84 & 36,56 \\
\hline Codemau & 54,74 & 35,20 \\
\hline Rio Grande do Sul & 85,10 & 37,96 \\
\hline
\end{tabular}

Fonte: Organizado pelos autores de acordo com dados do IBGE - Censo Demográfico 2010. 
Um dado interessante e que chama a atenção é que, no Brasil e mesmo no Rio Grande do Sul, $15 \%$ da população vive no meio rural, enquanto que, na região do Médio Alto Uruguai $45 \%$ da população permanece ainda no campo. Destaca-se uma redução de migração externa e um aumento na migração interna, ou seja, as pessoas deixam o interior, deslocando-se às cidades da região. Um número muito pequeno procura outros centros. A taxa de urbanização é de $54,74 \%$ do total da população, segundo dados do Censo/IBGE 2010.

\subsection{Razão de dependência}

A agregação da população residente nas faixas etárias que definem a População em Idade Ativa - PIA (de 15 a 64 anos de idade) e a fora da PIA (menos de 15 anos e mais que 65) foram definidas de acordo com a disponibilidade de dados obtidos através do Censo Demográfico 2010 do IBGE. Esta distribuição permite analisar a Razão de Dependência - RD, índice que mostra quantos dependentes existem para cada pessoa na PIA, ou seja, pressupõe que jovens e idosos são dependentes economicamente dos demais. Assim, é um indicador do contingente que pessoas suportadas pela população potencialmente produtiva. A Razão de Dependência Total - RDT pode ser decomposta em Razão de Dependência de Jovens - RDJ e Razão de Dependência de Idosos - RDI.

Tabela 3. Razão de Dependência nos municípios do Codemau

\begin{tabular}{|c|c|c|c|c|c|c|c|}
\hline \multirow{2}{*}{ Local } & \multicolumn{4}{|c|}{ Idades (anos) } & \multicolumn{3}{|c|}{$\mathrm{RD}(\%)$} \\
\hline & Menos de 15 & 15 a 64 & 65 ou mais & Total & Jovens & Idosos & Total \\
\hline Brasil & 45.932 .295 & 130.742 .024 & 14.081 .480 & 190.755 .799 & 35,13 & 10,77 & 45,90 \\
\hline Rio Grande do Sul & 2.274 .101 & 7.429 .943 & 989.885 & 10.693 .929 & 30,61 & 13,32 & 43,93 \\
\hline Alpestre & 1.635 & 5.459 & 933 & 8.027 & 29,95 & 17,09 & 47,04 \\
\hline Ametista do Sul & 1.803 & 4.972 & 548 & 7.323 & 36,26 & 11,02 & 47,28 \\
\hline Caiçara & 986 & $3 \cdot 512$ & 573 & 5.071 & 28,08 & 16,32 & 44,39 \\
\hline Cristal do Sul & 619 & 1.885 & 322 & 2.826 & 32,84 & 17,08 & 49,92 \\
\hline Dois Irmãos das Missões & 505 & 1.462 & 190 & 2.157 & 34,54 & 13,00 & 47,54 \\
\hline Erval Seco & 1.829 & 5.200 & 849 & 7.878 & 35,17 & 16,33 & 51,50 \\
\hline Frederico Westphalen & 5.790 & 20.616 & 2.437 & 28.843 & 28,08 & 11,82 & 39,91 \\
\hline Gramado dos Loureiros & 534 & 1.507 & 228 & 2.269 & 35,43 & 15,13 & 50,56 \\
\hline Iraí & 1.714 & 5.407 & 957 & 8.078 & 31,70 & 17,70 & 49,40 \\
\hline Nonoai & 2.857 & 7.963 & 1.254 & 12.074 & 35,88 & 15,75 & 51,63 \\
\hline Novo Tiradentes & 471 & 1.537 & 269 & 2.277 & 30,64 & 17,50 & 48,15 \\
\hline Palmitinho & 1.388 & 4.859 & 673 & 6.920 & 28,57 & 13,85 & 42,42 \\
\hline Pinhal & 500 & 1.756 & 257 & 2.513 & 28,47 & 14,64 & 43,11 \\
\hline Pinheirinho do Vale & 1.003 & 3.105 & 389 & 4.497 & 32,30 & 12,53 & 44,83 \\
\hline Planalto & 2.261 & 7.119 & 1.144 & 10.524 & 31,76 & 16,07 & 47,83 \\
\hline Rio dos Índios & 740 & 2.416 & 460 & 3.616 & 30,63 & 19,04 & 49,67 \\
\hline Rodeio Bonito & 1.163 & 4.019 & 561 & 5.743 & 28,94 & 13,96 & 42,90 \\
\hline Seberi & 2.312 & 7.384 & 1.201 & 10.897 & 31,31 & 16,26 & 47,58 \\
\hline Taquaruçu do Sul & 567 & 2.045 & 354 & 2.966 & 27,73 & 17,31 & 45,04 \\
\hline Trindade do Sul & 1.332 & 3.850 & 605 & 5.787 & 34,60 & 15,71 & 50,31 \\
\hline Vicente Dutra & 1.265 & 3.481 & 539 & 5.285 & 36,34 & 15,48 & 51,82 \\
\hline Vista Alegre & 578 & 1.962 & 292 & 2.832 & 29,46 & 14,88 & 44,34 \\
\hline
\end{tabular}

Fonte: IBGE - Censo Demográfico 2010 - Organização: autores. 
Quando a soma do número de jovens abaixo de 15 anos e dos adultos acima de 65 anos for menor do que a porção em idade produtiva, ocorre a chamada "oportunidade demográfica de desenvolvimento" ou "bônus demográfico", não somente em função do aumento da renda e do consumo/per capita no âmbito da família, mas também de mudanças possíveis na alocação de recursos por parte do poder público.

O Bônus Demográfico é, portanto, um fenômeno que ocorre em um período de tempo no qual a estrutura etária da população apresenta menores razões de dependência (baixa proporção de crianças, adolescentes e idosos) e maiores percentuais de população em idade economicamente ativa, possibilitando que as condições demográficas atuem no sentido de incrementar a qualidade de vida e reduzir os níveis de pobreza e desigualdade. Também pode contribuir para a redução das desigualdades de gênero, pois a queda das taxas de fecundidade e de mortalidade infantil transformam, em especial, a vida das mulheres, que dedicam menos tempo às tarefas da reprodução e do cuidado dos filhos, ganhando mais tempo para cuidar de si próprias, investir na qualificação profissional e se incorporar à população economicamente ativa $\mathrm{PEA}$.

Os dados apresentados na Tabela 3 demonstram que, na região em estudo, essa janela de oportunidades encontra-se fechada em cinco municípios, pois a razão de dependência, tanto de jovens quanto de idosos, apresenta valores muito elevados (acima de 50\%). Para ter uma ideia da dimensão do problema, no Brasil, a razão de dependência, em 2010, ficou em 45,9\%, ou seja, menos de 50 jovens e idosos para cada 100 em idade ativa. Com base nos dados, percebe-se que a região está na contramão desse processo, ou seja, em aproximadamente $70 \%$ dos municípios, os valores são superiores aos do Brasil, quando comparado aos do Estado do Rio Grande do Sul esse percentual elava-se a mais de $80 \%$. A média dos municípios do Codemau é de mais de 47 jovens e idosos para cada 100 em idade ativa. Os únicos municípios da região que ficaram abaixo da média do Estado foram Frederico Westphalen (39,91\%), Palmitinho (42,42\%), Rodeio Bonito (42,90\%) e Pinhal $(43,11 \%)$.

\subsection{Taxa de escolarização e analfabetismo}

Para obter a taxa de escolarização foram comparados os dados de população por faixa etária com os dados de matrícula inicial. Foram utilizados os dados disponibilizados pelo IBGE (Censo 2010) com a População Residente por Grupos de Idade. Dessa forma, considerou-se o número de crianças com idade entre o e 4 anos para avaliar a Taxa de Escolarização no Ensino Infantil, entre 5 e 14 anos para o Ensino Fundamental e entre 15 e 19 Ensino Médio. Em relação à educação infantil, nota-se o expressivo deficit no atendimento a crianças de até 5 anos de idade em todos os municípios do Codemau.

Considerando as matrículas no ano de 2010 com relação ao número de crianças, o atendimento só foi superior a 50\% em quatro municípios do Codemau. Conforme dados do Gráfico 1, o município com melhor atendimento é Taquaruçu do Sul e, mesmo assim, há carência para 31,47\% de suas crianças. Pinheirinho do Vale está em segundo lugar, com 33,72\% sem atendimento, seguido de Dois Irmãos das Missões e Rodeio Bonito, onde 33,77 e 38,60\% das crianças estão desassistidas. 
Gramado dos Loureiros é o município com o pior desempenho, pois $81,82 \%$ das crianças com idade entre o e 5 anos de idade não são atendidas, o que acarreta transtornos no desenvolvimento de crianças de até 4 anos de idade. Esses transtornos vêm se somar a dificuldades na transição para o nível fundamental.

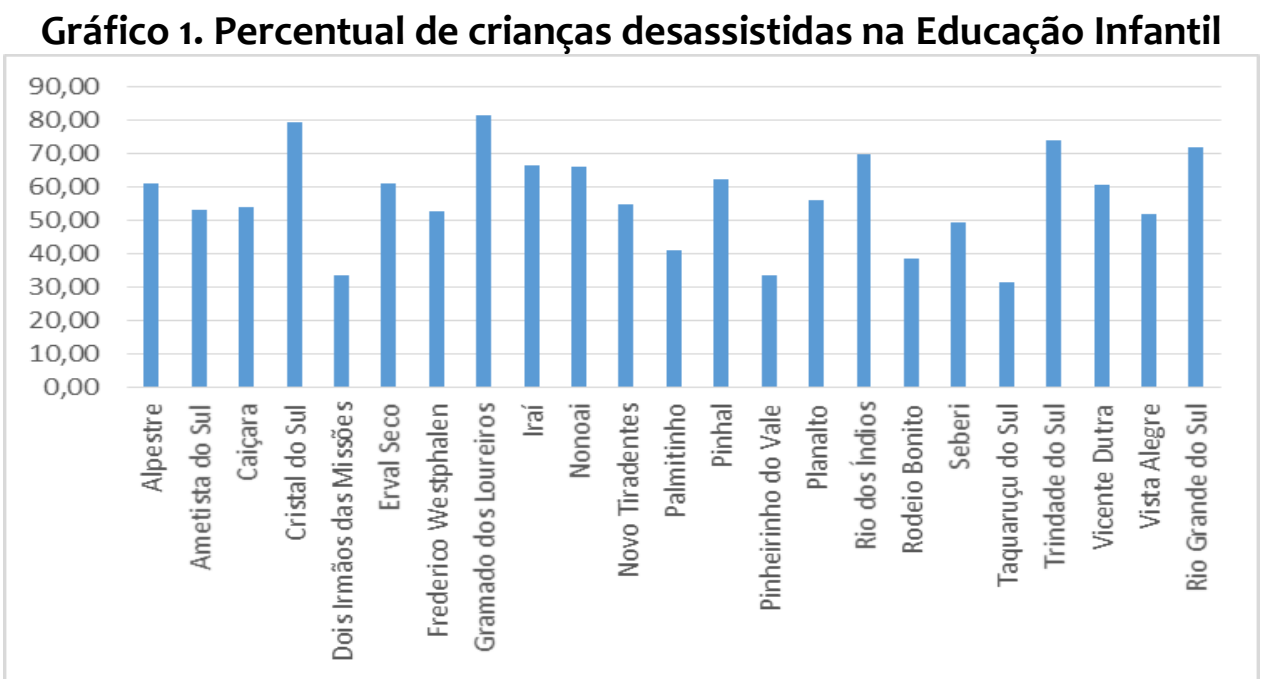

Fonte: elaborado pelos autores com base nos dados do Censo do IBGE 2010.

A região do Codemau possui uma alta taxa de analfabetismo, chegando à marca de $9,42 \%$, sendo uma das mais altas do Estado. O analfabetismo se concentra principalmente na área rural, situação que decorre do processo de desestruturação e da falta de investimento e atenção ao ensino rural.

As taxas de analfabetismo dos municípios em estudo podem ser visualizadas na Tabela 4. Nenhum dos municípios da região apresentou taxas inferiores à do Estado do Rio Grande do Sul. Somente Frederico Westphalen, que tem a menor taxa na região, ficou próximo da taxa do Estado, 4,64\% contra 4,53\%. Já, o Município de Rio dos Índios apresentou a maior taxa de analfabetismo entre a população de 15 anos ou mais de idade, com $14,85 \%$. 
Tabela 4. Taxa de Analfabetismo nos municípios do CODEMAU

Município

Alpestre

Ametista do Sul

Caiçara

Cristal do Sul

Dois Irmãos das Missões

Erval Seco

Frederico Westphalen

Gramado dos Loureiros

Iraí

Nonoai

Novo Tiradentes

Palmitinho

Pinhal

Pinheirinho do Vale

Planalto

Rio dos Índios

Rodeio Bonito

Seberi

Taquaruçu do Sul

Trindade do Sul

Vicente Dutra

Vista Alegre

Rio Grande do Sul

Fonte: elaborado pelos autores com base nos dados da FEE

- Perfil Socioeconômico.
Analfabetismo 15 anos ou

mais (\%)

12,73

11,41

7,59

12,19

12,29

11,64

4,64

12,80

9,44

11,02

15,28

8,95

9,34

10,36

11,29

14,85

7,93

8,00

8,63

11,56

10,97

7,23

4,53

Em 2014, o Fórum dos Coredes-RS elaborou um "Plano de Diretrizes", o qual foi entregue aos candidatos a governador do Estado do Rio Grande do Sul, legislatura 2015/2018. O Codemau, na busca por reverter essa situação desfavorável, elaborou o seu plano abrangendo os 22 municípios da região, apresentando dez Programas Estruturantes, com foco na realidade regional, respeitando a sua vocação, com base no Plano Estratégico de Desenvolvimento Regional, construído no período de 2008 a 2010 pela comunidade regional. No tocante ao plano educacional, destacam-se resumidamente os principais desdobramentos:

- Capacitar e qualificar continuamente os professores do ensino básico da região;

- Oferecer infraestrutura básica para as escolas da região;

- Dotar as secretarias municipais de educação de veículos novos para efetuar o transporte de alunos e professores;

- Oferecer e oportunizar ensino técnico e tecnológico para a comunidade regional;

- Criar novos cursos técnicos e tecnológicos, observando a vocação regional;

- Estabelecer programas de apoio aos estudantes dos cursos técnicos e superiores;

- Ampliar a oferta de cursos superiores nas instituições de ensino da região;

- Ampliar o número de bolsas de estudo para os cursos superiores em universidades particulares; 
- Desenvolver um programa de educação continuada em parceria com as instituições de ensino da região;

- Implantar uma Coordenadoria Regional de Educação - CRE na região do Codemau.

\subsection{Distribuição da economia do Codemau por segmento econômico}

Observa-se, na Figura 2, que a produção primária, advinda do setor agropecuário, deixou de ser a principal atividade econômica regional. Segundo dados do Codemau (2017) em 2011 esta atividade representava 37,55\% de toda a produção regional, contra $34,49 \%$ da indústria. Já em 2012, a contribuição dessas atividades se inverteu, tendo a indústria assumido o papel de principal atividade, com $37,02 \%$ contra $35,30 \%$ da produção agropecuária.

Ressalva-se que essa inversão não significa que a produção primária da região deixa de ser importante, mas, sim, que ocorreu um substancial incremento da indústria na formação da economia regional, já que a geração de energia da Foz do Chapecó no Município de Alpestre integra este segmento, bem como do processo crescente de agro industrialização.

Figura 2. Distribuição da economia regional por segmento econômico

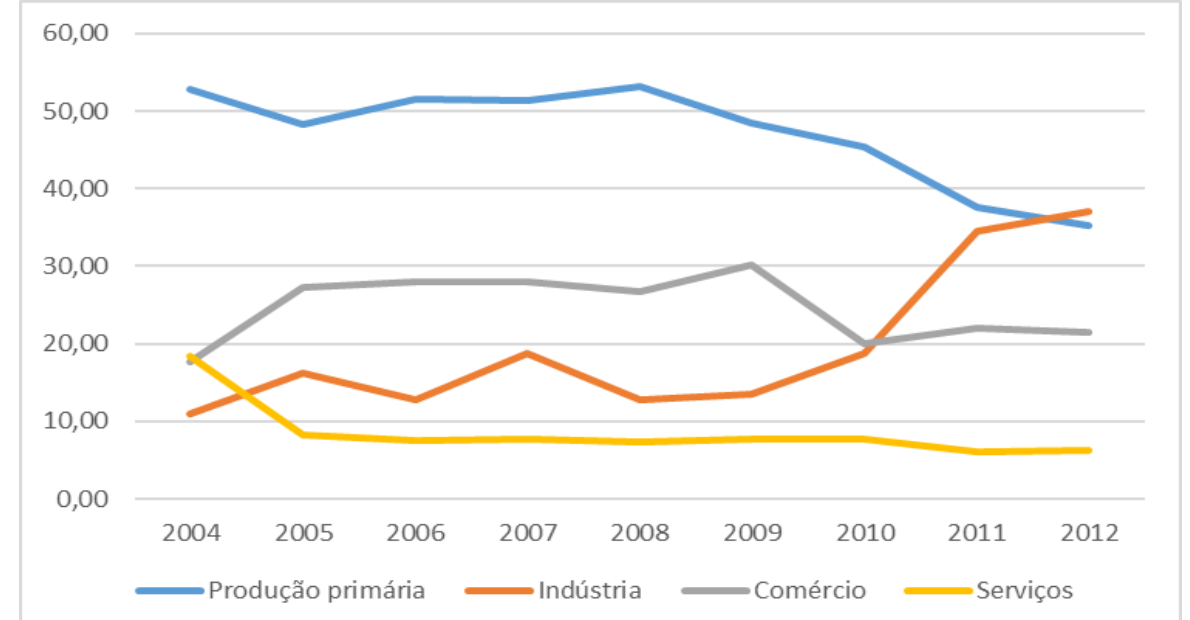

Fonte: elaborado pelos autores com base nos dados do Codemau (2017).

O setor de serviços apresenta tendência estável nos últimos anos na participação da economia regional. O comércio apresentou queda acentuada de 2009 para 2010, mantendo-se estável nos dois últimos anos.

De acordo com os dados apresentados, verifica-se a importância da indústria na formação da economia regional, que cresceu de forma acentuada a partir de 2010. Assim cabe destacar a necessidade de se investir mais neste setor, pois a região precisa se desenvolver cada vez mais para deixar de ser uma região em transição e ser considerada em desenvolvimento. 


\section{6 Índice de Desenvolvimento Humano Municipal}

O Índice de Desenvolvimento Humano - IDH, de forma qualitativa, sinaliza a evolução do desenvolvimento socioeconômico de uma determinada localidade. Este indicador é uma medida geral usada para considerar o grau de desenvolvimento econômico e a qualidade de vida dos países. Criado em 1990, vem sendo publicado anualmente desde 1993 pelo PNUD. O índice varia em uma escala que vai de zero, ou seja, nenhum desenvolvimento, até 1 , que representa desenvolvimento humano total. Atualmente, as três dimensões que constituem o IDH são:

- Saúde: Vida saudável e longa (medida pela expectativa de vida);

- Educação: Acesso ao conhecimento (medido pela média de anos de educação de adultos e a expectativa de anos de escolaridade para crianças na idade de iniciar a vida escolar); e

- Renda: Padrão de vida (medido pela Renda Nacional Bruta per capita).

No decorrer do ano de 2012, o PNUD do Brasil, o Instituto de Pesquisa Econômica Aplicada - IPEA e a Fundação João Pinheiro - FJP assumiram o desafio de adaptar o método do IDH global para calcular o IDH-M dos 5.565 municípios brasileiros a partir de dados do Censo Demográfico de 2010.

De acordo com o Atlas (2013), o IDH-M é composto por mais de 180 indicadores socioeconômicos, que dão suporte à sua análise e ampliam a compreensão dos fenômenos e dinâmicas voltados ao desenvolvimento municipal. Os procedimentos metodológicos empregados na composição do índice possibilita determinar se uma melhora ocorrida em um município decorre da adoção de políticas específicas ou se o resultado obtido é apenas reflexo da queda dos demais municípios. Para efeito de análise comparada, o PNUD-Brasil estabeleceu cinco principais categorias para avaliar o Índice de IDH-M, apresentada na Figura 3.

Figura 3. Faixas de Desenvolvimento Humano Municipal

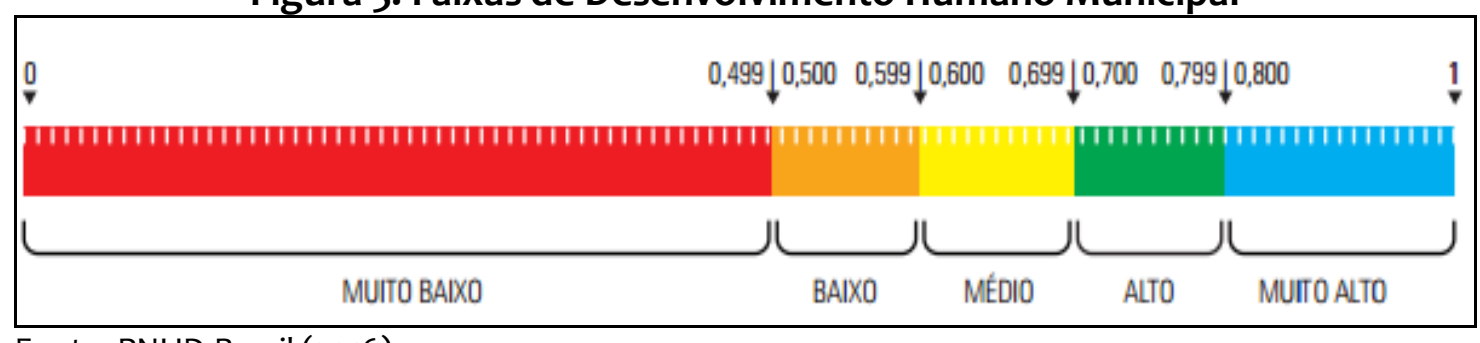

Fonte: PNUD-Brasil (2016).

De acordo com o Atlas do Desenvolvimento Humano no Brasil (2013) ao considerar o Índice de IDH-M, (que corresponde à educação, renda e longevidade) nos municípios que pertencem ao Codemau, constata-se que os melhores no ano de 2000 foram os municípios de Frederico Westphalen (0,683) e Rodeio Bonito $(0,642)$. Ao passo que os piores eram os municípios de Vicente Dutra $(0,489)$ e Rio dos Índios $(0,512)$, enquanto o melhor pertencia ao extrato de desenvolvimento médio $(0,600$ a 0,699) e o pior situava-se no extrato muito baixo (0,000 a 0,499). Já com relação ao IDH-M - 2010, os melhores índices são dos municípios de Frederico Westphalen (0,760), Taquaruçu do Sul e Vista Alegre, ambos com $(0,739)$. Percebese que quando comparado ao ano 2000 nenhum dos municípios do Codemau 
permaneceu no extrato baixo. Destaque para os municípios de Nonoai, Pinheirinho do Vale e Seberi que, no período de dez anos, passaram do extrato baixo para o alto. Cabe destacar também o Município de Vicente Dutra, que, no ano de 2000, ocupava o extrato muito baixo com 0,489 e no período analisado avançou dois extratos, passando de muito baixo (menor que 0,499$)$ para médio $(0,638)$.

Tabela 5. Índice de Desenvolvimento Humano Municipal - 2000/2010

\begin{tabular}{|c|c|c|c|c|c|c|c|c|}
\hline \multirow[b]{3}{*}{ Municípios } & \multicolumn{8}{|c|}{ IDHM } \\
\hline & \multicolumn{3}{|c|}{2000} & \multicolumn{5}{|c|}{2010} \\
\hline & $\begin{array}{l}\frac{\overline{0}}{\mathbf{1}} \\
\frac{1}{3}\end{array}$ & $\begin{array}{l}\stackrel{D}{D} \\
\stackrel{D}{D} \\
\stackrel{\alpha}{\alpha}\end{array}$ & 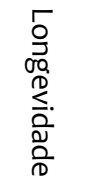 & 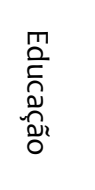 & $\begin{array}{l}\bar{\nabla} \\
\frac{1}{3}\end{array}$ & $\begin{array}{l}\text { D } \\
\text { D } \\
\text { م⿱ 口) }\end{array}$ & 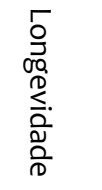 & 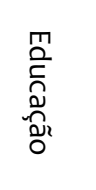 \\
\hline Alpestre & 0,524 & 0,564 & 0,769 & 0,332 & 0,671 & 0,700 & 0,795 & 0,543 \\
\hline Ametista do Sul & 0,539 & 0,627 & 0,723 & 0,346 & 0,682 & 0,697 & 0,809 & 0,562 \\
\hline Caiçara & 0,612 & 0,635 & 0,794 & 0,454 & 0,699 & 0,721 & 0,817 & 0,580 \\
\hline Cristal do Sul & 0,516 & 0,489 & 0,775 & 0,362 & 0,660 & 0,641 & 0,826 & 0,542 \\
\hline Dois Irmãos das Missões & 0,559 & 0,588 & 0,703 & 0,423 & 0,670 & 0,646 & 0,797 & 0,585 \\
\hline Erval Seco & 0,538 & 0,571 & 0,757 & 0,360 & 0,685 & 0,666 & 0,821 & 0,589 \\
\hline Frederico Westphalen & 0,683 & 0,689 & 0,813 & 0,569 & 0,760 & 0,754 & 0,846 & 0,688 \\
\hline Gramado dos Loureiros & 0,573 & 0,579 & 0,737 & 0,442 & 0,685 & 0,662 & 0,832 & 0,584 \\
\hline Iraí & 0,595 & 0,662 & 0,790 & 0,403 & 0,691 & 0,684 & 0,819 & 0,590 \\
\hline Nonoai & 0,584 & 0,628 & 0,775 & 0,409 & 0,702 & 0,703 & 0,833 & 0,591 \\
\hline Novo Tiradentes & 0,538 & 0,529 & 0,757 & 0,389 & 0,676 & 0,679 & 0,805 & 0,566 \\
\hline Palmitinho & 0,615 & 0,635 & 0,772 & 0,474 & 0,720 & 0,707 & 0,836 & 0,632 \\
\hline Pinhal & 0,628 & 0,701 & 0,792 & 0,446 & 0,720 & 0,701 & 0,852 & 0,624 \\
\hline Pinheirinho do Vale & 0,530 & 0,577 & 0,748 & 0,345 & 0,710 & 0,713 & 0,828 & 0,607 \\
\hline Planalto & 0,587 & 0,617 & 0,737 & 0,444 & 0,687 & 0,674 & 0,807 & 0,597 \\
\hline Rio dos Índios & 0,512 & 0,559 & 0,776 & 0,309 & 0,656 & 0,645 & 0,804 & 0,545 \\
\hline Rodeio Bonito & 0,642 & 0,667 & 0,793 & 0,501 & 0,732 & 0,733 & 0,842 & 0,636 \\
\hline Seberi & 0,597 & 0,619 & 0,794 & 0,433 & 0,723 & 0,706 & 0,865 & 0,620 \\
\hline Taquaruçu do Sul & 0,588 & 0,607 & 0,794 & 0,421 & 0,739 & 0,768 & 0,830 & 0,633 \\
\hline Trindade do Sul & 0,561 & 0,568 & 0,769 & 0,405 & 0,687 & 0,675 & 0,787 & 0,610 \\
\hline Vicente Dutra & 0,489 & 0,550 & 0,757 & 0,281 & 0,638 & 0,656 & 0,809 & 0,489 \\
\hline Vista Alegre & 0,632 & 0,613 & 0,803 & 0,514 & 0,739 & 0,760 & 0,842 & 0,631 \\
\hline Rio Grande do Sul & 0,552 & 0,608 & 0,700 & 0,396 & 0,684 & 0,678 & 0,792 & 0,597 \\
\hline
\end{tabular}




\section{7 Índice Desenvolvimento Socioeconômico - IDESE}

Segundo a FEE, O Idese é um indicador-síntese que tem o propósito de mensurar o nível de desenvolvimento dos municípios do Rio Grande do Sul. O objetivo de se divulgar o Idese é avaliar e acompanhar a evolução dos indicadores socioeconômicos dos municípios do Estado, bem como fornece informações para o desenho de políticas públicas específicas de acordo com as necessidades municipais. O Idese é composto por 12 indicadores, dividido em três blocos: Educação, Renda e Saúde. De acordo com a FEE (2015), cada um dos blocos, por sua vez, resulta da agregação de diferentes variáveis.

O Bloco Educação do Idese utiliza cinco indicadores que se dividem em quatro sub-blocos, de acordo com faixas etárias: 1) população entre quatro e cinco anos (pré-escola) - Taxa de matrícula na pré-escola; 2) população entre 6 e 14 anos (ensino fundamental) - Nota da Prova Brasil do $5^{\circ}$ ano do ensino fundamental e Nota da Prova Brasil do $9^{\circ}$ ano do ensino fundamental; 3) população entre 15 e 17 anos (ensino médio) - Taxa de matrícula no ensino médio; e 4) população com 18 anos ou mais (escolaridade adulta) - Percentual da população adulta com, pelo menos, o ensino fundamental completo. À exceção do sub-bloco "1", os demais são compostos por indicadores de matrícula ou escolarização. O sub-bloco "1", relacionado às crianças com idade entre seis e 14 anos, diferencia-se dos outros por ser o único composto por dois indicadores de qualidade no ensino fundamental. $O$ índice final do Bloco Educação é a média aritmética dos índices desses sub-blocos.

Já o Bloco Saúde utiliza cinco indicadores que são divididos em três subblocos: (1) saúde materno-infantil - Taxa de mortalidade de menores de cinco anos; Número de consultas pré-natais por nascidos vivos; (2) condições gerais de saúde Taxa de mortalidade por causas evitáveis; Proporção de óbitos por causas mal definidas; e (3) longevidade - Taxa bruta de mortalidade padronizada - TBMP. O índice final do Bloco Saúde é a média aritmética dos índices desses sub-blocos. No primeiro sub-bloco, estão inseridos dois indicadores: (a) taxa de mortalidade de menores de cinco anos; e (b) números de consultas pré-natais por nascidos vivos. $O$ segundo sub-bloco, condições gerais de saúde, é constituído, por sua vez, pelos indicadores: (a) taxa de mortalidade por causas evitáveis e (b) proporção de óbitos por causas mal definidas. O indicador (a) taxa de mortalidade bruta padronizada completa o Bloco Saúde, ao formar o sub-bloco longevidade.

Por fim, o Bloco Renda é composto por dois sub-blocos que analisam a renda por duas óticas distintas: (1) apropriação de renda - Renda domiciliar per capita média; e (2) geração de renda - PIB per capita. Cada sub-bloco contém apenas um indicador. $O$ índice final do Bloco Renda é a média aritmética de seus sub-blocos.

Para cada variável dos blocos é calculado um índice, entre o (nenhum desenvolvimento) e 1 (desenvolvimento total), que indica a posição relativa para os municípios. Com esse fim, são fixados, a partir de parâmetros internacionais, os valores de referência máxima (1) e mínimo (0) de cada variável. Os índices dos blocos são obtidos por meio de uma média ponderada dos índices de cada variável componente do bloco.

A metodologia de cálculo do Idese sofreu alterações, porém o valor continua sendo mínimo o (zero) e o máximo 1 (um), podendo nos cálculos identificar as variações de melhor desempenho e as que sinalizam mais deficiências. 
$\mathrm{Na}$ Figura 4, apresenta-se evolução do Idese no período de 2007 a 2014 (últimos dados disponíveis), com base na nova metodologia do cálculo. Observa-se que a região teve uma dinâmica parecida com o Estado na evolução do índice, o que demonstra que está mudando o quadro de desenvolvimento da região em termos de qualidade de vida de sua população.

Figura 4. Evolução do Idese no período de 2007 a 2014

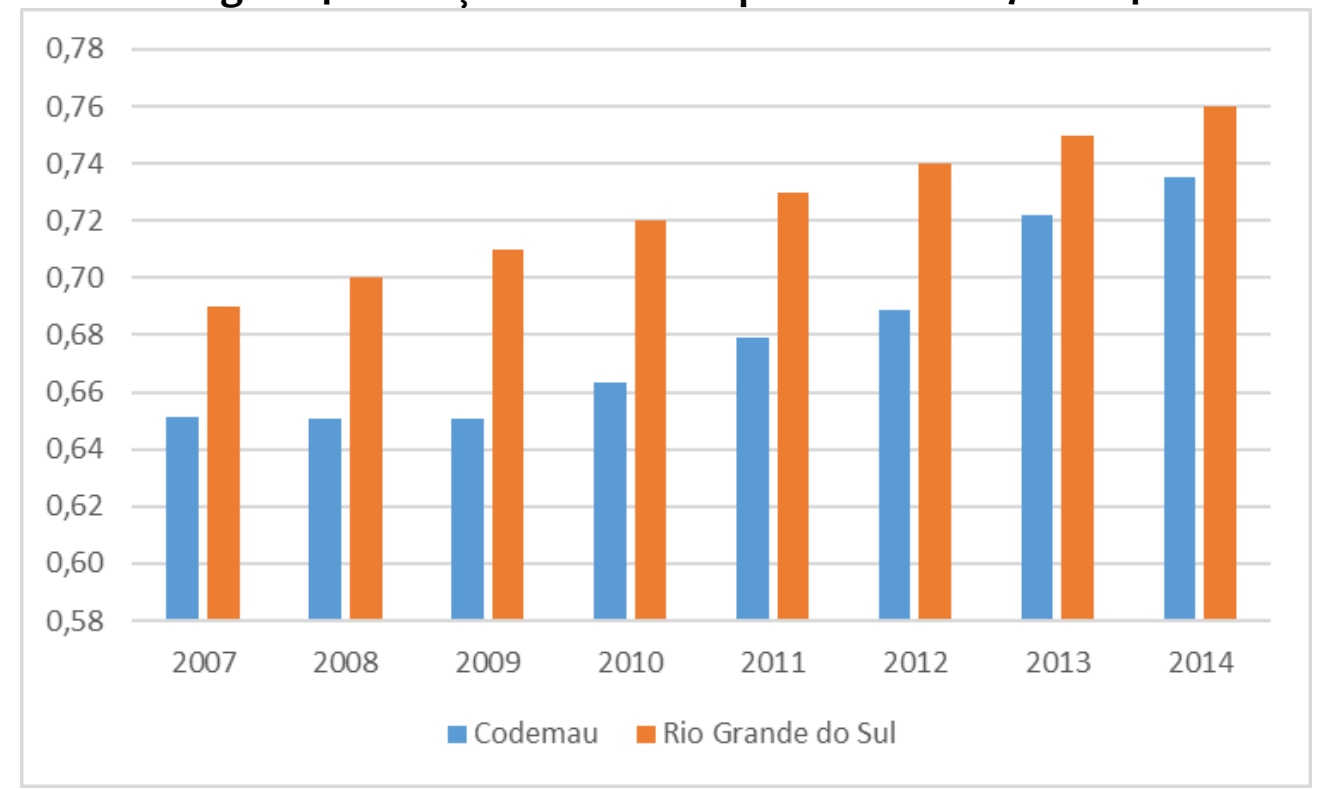

Fonte: FEE/RS - Org.: Equipe do Codemau.

Os índices por município podem ser observados na Tabela 7, bem como os índices do Estado. Percebe-se que, de todos os municípios do Codemau, apenas Frederico Westphalen apresentou redução do índice no período analisado (1,25\%). Com acréscimo no índice superior a 20\% destacam-se Gramado dos Loureiros, Pinheirinho do Vale e Caiçara, com taxas de crescimento de $25,42 \%, 22,58 \%$ e $20,97 \%$, respectivamente. 
Tabela 7. Idese dos Municípios do Codemau e RS, período 2007 a 2012*

\begin{tabular}{lcccccccc}
\hline \multicolumn{1}{c}{ Local } & \multicolumn{10}{c}{ IDESE } \\
\hline Alpestre & 2007 & 2008 & 2009 & 2010 & 2011 & 2012 & 2013 & 2014 \\
Ametista do Sul & 0,62 & 0,61 & 0,61 & 0,66 & 0,69 & 0,69 & 0,70 & 0,72 \\
Caiçara & 0,61 & 0,61 & 0,61 & 0,61 & 0,61 & 0,65 & 0,68 & 0,70 \\
Cristal do Sul & 0,62 & 0,62 & 0,62 & 0,71 & 0,74 & 0,74 & 0,74 & 0,75 \\
Dois Irmãos das Missões & 0,59 & 0,58 & 0,57 & 0,62 & 0,63 & 0,63 & 0,67 & 0,69 \\
Erval Seco & 0,63 & 0,63 & 0,62 & 0,70 & 0,73 & 0,71 & 0,76 & 0,75 \\
Frederico Westphalen & 0,65 & 0,65 & 0,65 & 0,64 & 0,67 & 0,67 & 0,72 & 0,75 \\
Gramado dos Loureiros & 0,80 & 0,80 & 0,79 & 0,75 & 0,77 & 0,76 & 0,77 & 0,79 \\
Iraí & 0,59 & 0,59 & 0,59 & 0,62 & 0,66 & 0,68 & 0,74 & 0,74 \\
Nonoai & 0,68 & 0,68 & 0,68 & 0,66 & 0,66 & 0,68 & 0,70 & 0,71 \\
Novo Tiradentes & 0,69 & 0,70 & 0,72 & 0,66 & 0,69 & 0,69 & 0,73 & 0,73 \\
Palmitinho & 0,62 & 0,63 & 0,63 & 0,67 & 0,69 & 0,69 & 0,71 & 0,72 \\
Pinhal & 0,66 & 0,66 & 0,66 & 0,65 & 0,65 & 0,65 & 0,73 & 0,74 \\
Pinheirinho do Vale & 0,70 & 0,69 & 0,70 & 0,70 & 0,72 & 0,71 & 0,75 & 0,76 \\
Planalto & 0,62 & 0,62 & 0,62 & 0,66 & 0,70 & 0,72 & 0,74 & 0,76 \\
Rio dos Índios & 0,66 & 0,66 & 0,66 & 0,64 & 0,67 & 0,66 & 0,69 & 0,71 \\
Rodeio Bonito & 0,62 & 0,63 & 0,62 & 0,61 & 0,62 & 0,64 & 0,71 & 0,72 \\
Seberi & 0,70 & 0,70 & 0,70 & 0,68 & 0,70 & 0,71 & 0,73 & 0,76 \\
Taquaruçu do Sul & 0,66 & 0,66 & 0,67 & 0,69 & 0,69 & 0,70 & 0,73 & 0,75 \\
Trindade do Sul & 0,66 & 0,65 & 0,65 & 0,71 & 0,74 & 0,73 & 0,74 & 0,77 \\
Vicente Dutra & 0,68 & 0,68 & 0,68 & 0,67 & 0,66 & 0,66 & 0,70 & 0,71 \\
Vista Alegre & 0,60 & 0,59 & 0,59 & 0,59 & 0,52 & 0,63 & 0,66 & 0,66 \\
Rio Grande do Sul & 0,67 & 0,67 & 0,67 & 0,70 & 0,73 & 0,75 & 0,78 & 0,78 \\
\hline Fontery & 0,69 & 0,70 & 0,71 & 0,72 & 0,73 & 0,74 & 0,75 & 0,76 \\
\hline
\end{tabular}

Fonte: FEE/RS - Org.: Equipe do Codemau (2016).

*Índice baseado na nova metodologia que excluiu o saneamento básico do cálculo (o mesmo está incluído no bloco saúde).

\subsection{PIB e Renda Per Capita}

Por meio de uma análise estatística dos dados apresentados na Tabela 6, é possível verificar que a média do PIB nos municípios pertencentes ao Codemau é de $\mathrm{R} \$$ 138.234.668,59, valor este puxado por municípios como Erval Seco, Frederico Westphalen, Nonoai e Seberi. No somatório de todos os municípios do Corede, não chega nem a $1 \%$ do valor total do Estado. Quando analisado pela ótica da renda per capita a média para o Corede é de apenas $\mathrm{R} \$ 19.500,66$, com desvio padrão de $\mathrm{R} \$$ $6.475,19$, muito inferior aos valores médios do país e do estado.

No que se refere à renda per capita, indicador que auxilia o conhecimento sobre o grau de desenvolvimento de um país e incide na divisão do coeficiente da renda nacional (produto nacional bruto subtraído dos gastos de depreciação do capital e os impostos indiretos) pela sua população, percebe-se, através dos dados da FEE de 2015, que somente o Município de Dois Irmãos das Missões apresentou valor superior ao do Estado do Rio Grande do Sul no ano de 2013, R\$ 40.785,17 frente a $\mathrm{R} \$ 29.657,28$. Outro dado relevante é de que nenhum dos municípios do Corede, fora Dois Irmãos das Missões, apresentaram valor superior à renda per capita nacional, que foi de $\mathrm{R} \$ 26.445,72$ no ano de 2013 . O município de Frederico 
Westphalen ficou muito próximo deste valor, mas bem abaixo do Estado. Ametista do Sul apresentou valor inferior a $1 / 3$ da renda per capita do Estado e Planalto não atingiu nem a metade do valor e fecharam o ano de 2013 com renda per capita de $\mathrm{R} \$$ 9.596,81 e $\mathrm{R} \$ 12.734,42$ respectivamente.

O cenário dos municípios do Corede em relação ao Estado torna-se ainda mais preocupante quando se observa a posição dos mesmos no total dos municípios gaúchos, sendo que o município melhor classificado ocupa a quinquagésima nona posição de um total de 497 municípios, e o Município de Ametista do Sul ocupa a última posição do ranking estadual, com valor inferior a $\mathrm{R} \$$ 10.000,00.

Tabela 6. PIB e Renda Per Capita dos municípios do Codemau - 2013

\begin{tabular}{|c|c|c|}
\hline Município & PIB (R\$) & Renda Per Capita (R\$̣) \\
\hline Alpestre & 110.236 .181 & $14.005,36$ \\
\hline Ametista do Sul & 72.551 .921 & $9 \cdot 596,81$ \\
\hline Caiçara & 80.568 .382 & $15.650,42$ \\
\hline Cristal do Sul & $45 \cdot 338.737$ & $15 \cdot 553,60$ \\
\hline Dois Irmãos das Missões & 89.401 .089 & $40.785,17$ \\
\hline Erval Seco & 193.177 .535 & $24 \cdot 455,95$ \\
\hline Frederico Westphalen & 789.981 .063 & $26.114,21$ \\
\hline Gramado dos Loureiros & 40.343 .588 & $17 \cdot 578,91$ \\
\hline Iraí & 123.553 .495 & $15.193,49$ \\
\hline Nonoai & 282.854 .828 & $22.906,93$ \\
\hline Novo Tiradentes & 42.288 .073 & $18.149,39$ \\
\hline Palmitinho & 130.112 .787 & $18.182,33$ \\
\hline Pinhal & 56.474 .795 & $21.704,38$ \\
\hline Pinheirinho do Vale & 65.188 .266 & $13.825,72$ \\
\hline Planalto & 136.754 .988 & $12.734,42$ \\
\hline Rio dos Índios & 71.235 .205 & $20.174,23$ \\
\hline Rodeio Bonito & 114.542 .166 & $19.276,70$ \\
\hline Seberi & 258.830 .770 & $23.134,68$ \\
\hline Taquaruçu do Sul & 78.700 .767 & $25 \cdot 568,80$ \\
\hline Trindade do Sul & 128.604 .943 & $21.570,77$ \\
\hline Vicente Dutra & 77.578 .005 & $14.623,56$ \\
\hline Vista Alegre & 52.845 .125 & $18.228,74$ \\
\hline Rio Grande do Sul & 331.095 .182 .854 & $29.657,28$ \\
\hline
\end{tabular}

\section{9 Índice de Gini}

Desenvolvido pelo estatístico italiano Corrado Gini em 1912, este índice é obtido através da curva de Lorenz, desenvolvida pelo economista americano Max Lorenz em 1905. Consiste em um número entre 0 e 1, sendo que o corresponde à completa igualdade (no caso do rendimento, por exemplo, toda a população recebe o mesmo salário) e 1 corresponde à completa desigualdade (uma pessoa recebe todo o rendimento e as demais nada recebem).

Entre 2000 e 2010, o Índice de Gini, que mede a desigualdade de renda, do 
Rio Grande do Sul diminuiu de 0,58 para 0,54, indicando que houve uma redução da desigualdade no Estado. Organizações internacionais como o PNUD e a Organização Internacional do Trabalho - OIT têm apontado para a necessidade de diminuir as desigualdades sociais e garantir a justiça social, permitindo que todos os cidadãos tenham acesso a oportunidades e possam desenvolver suas capacidades de maneira mais equitativa.

Tabela 8. Índice de Gini Brasil, Rio Grande do Sul e municípios do Codemau

\begin{tabular}{lcc}
\hline \multicolumn{1}{c}{ Local } & Índice de Gini (2000) & Índice de Gini (2010) \\
\hline Brasil & 0,64 & 0,60 \\
Rio Grande do Sul & 0,58 & 0,54 \\
Alpestre & 0,59 & 0,49 \\
Ametista do Sul & 0,57 & 0,58 \\
Caiçara & 0,57 & 0,47 \\
Cristal do Sul & 0,52 & 0,45 \\
Dois Irmãos das Missões & 0,63 & 0,50 \\
Erval Seco & 0,57 & 0,52 \\
Frederico Westphalen & 0,54 & 0,47 \\
Gramado dos Loureiros & 0,52 & 0,50 \\
Iraí & 0,64 & 0,54 \\
Nonoai & 0,62 & 0,50 \\
Novo Tiradentes & 0,47 & 0,40 \\
Palmitinho & 0,54 & 0,42 \\
Pinhal & 0,77 & 0,45 \\
Pinheirinho do Vale & 0,50 & 0,57 \\
Planalto & 0,58 & 0,44 \\
Rio dos Índios & 0,57 & 0,49 \\
Rodeio Bonito & 0,58 & 0,46 \\
Seberi & 0,57 & 0,52 \\
Taquaruçu do Sul & 0,56 & 0,53 \\
Trindade do Sul & 0,55 & 0,49 \\
Vicente Dutra & 0,51 & 0,50 \\
Vista Alegre & 0,48 & 0,57 \\
\hline Fonte & & 0,56 \\
\hline
\end{tabular}

Fonte: elaborado pelos autores com base nos dados do Atlas do Desenvolvimento Humano no Brasil, PNUD (2013).

Dentre os municípios do Codemau, o município que apresentou menor desigualdade em 2010 foi Novo Tiradentes, com um índice de Gini de 0,40, e o município com maior desigualdade em 2010 foi Ametista do Sul, com índice de Gini de 0,58 . Deve-se considerar que o aprofundamento das desigualdades econômicas e sociais passou a ser atualmente uma das maiores preocupações globais. Quando comparados ao índice do Brasil, todos os municípios do Corede apresentam concentração de renda menor, Já Ametista do Sul, Pinheirinho do Vale e Vista Alegre apresentaram valores superiores aos do Estado do Rio Grande do Sul.

Considerando a média dos municípios do Codemau para o ano 2000, que foi de 0,565 com desvio padrão de 0,064, pode-se dizer que os municípios estão muito próximos da média do Estado do Rio Grande do Sul $(0,58)$ e inferiores à média 
nacional $(0,64)$, sendo o menor valor em Novo Tiradentes do Sul $(0,47)$ e o maior em Pinhal $(0,77)$. Já em 2010, os municípios do Codemau apresentaram valores muito mais significativos, com média de 0,494 e desvio padrão de 0,047. Comparado aos dados do Estado do Rio Grande do Sul $(0,54)$ e do Brasil $(0,60)$, pode-se dizer que, de acordo com os dados do PNUD, o Codemau apresentou redução da desigualdade.

\section{CONSIDERAÇÕES FINAIS}

Esta pesquisa concentrou-se em municípios da região do Codemau buscando apresentar e discutir os indicadores do crescimento econômico e do desenvolvimento destes municípios. A discussão dos indicadores socioeconômicos é de grande relevância para a compreensão da realidade complexa de uma determinada região.

A região do Médio Alto Uruguai é considerada uma das regiões do Estado com baixo PIB e Idese, tendo grandes problemas e gargalos, enfrentando dificuldade quanto a investimentos que venham a gerar novos postos de trabalho $e$ renda, contribuindo, desta forma, para a permanência da população na região.

Foi possível verificar ainda, por meio da análise do índice de Gini, que a desigualdade vem diminuindo entre vários municípios do Corede, aumentando, no período de 2000 a 2010, em Ametista do Sul de 0,57 para 0,58, em Pinheirinho do Vale de 0,50 para 0,57 e em Vista Alegre de 0,48 para 0,57, o pior incremento de desigualdade entre os municípios do Codemau.

Torna-se necessário pensar o desenvolvimento sob o âmbito social, econômico e ambiental. Essas três áreas podem estar entrelaçadas para que ocorra um novo tipo de desenvolvimento, diminuindo as desigualdades socioeconômicas entre municípios e regiões, possibilitando, assim, uma renda mais igualitária. Acredita-se que o debate sobre o que é desenvolvimento é algo que está sendo construído. Ao idealizar desenvolvimento como sendo a ampliação das liberdades individuais e coletivas, situações de municípios com PIB per capita extremamente elevado, alta concentração de renda e, em contraposição, um IDH baixo, deverá ser repensado. A discussão sobre indicadores econômicos e sociais possibilitam pensar o desenvolvimento em longo prazo, com a valorização das regiões e do local, trabalhando localidades com suas particularidades e potencialidades, buscando alcançar um desenvolvimento regional sustentável e não mais somente pelo prisma econômico.

Para trabalhos futuros, sugere-se abordar a arrecadação dos municípios do Codemau e a infraestrutura básica oferecida à população. Dessa forma, é possível conhecer os problemas e construir políticas públicas que possam sanar e reduzir as disparidades regionais encontradas nos municípios em estudo.

\section{REFERÊNCIAS}

ATLAS DO DESENVOLVIMENTO HUMANO. Banco de dados IDH-M. Disponível em: <http://www.atlasbrasil.org.br/2013/pt/o_atlas/idhm/>. Acesso em: 4 set. 2016. 
BOISIER, S. Desenvolvimento. In.: SIEDENBERG. D. R. (coordenador). Dicionário de Desenvolvimento Regional. Santa Cruz do Sul: EDUNISC, 2006, p.69.

CONSELHO REGIONAL DE DESENVOLVIMENTO REGIONAL - CODEMAU. In: GIRARDI, Edemar (Org.) et al. Plano estratégico de desenvolvimento da região do Médio Alto Uruguai: 2015-2030. CODEMAU - Frederico Westphalen, RS: Grafimax, 2017.

Disponível em:

<http://www.codemau.org.br/>. Acesso em: 11 jun. 2016.

DELEVATI, D.M. Organização Social e desenvolvimento regional. In: VOGT, O.S. Vale do Rio Pardo: (re) conhecendo a região. Santa Cruz do Sul: EDUNISC. 2001.

DUPAS. G. O mito do progresso. São Paulo: Unesp, 2006.309p.

FUNDAÇÃO DE ECONOMIA E ESTATÍSTICA - FEE. RS em Mapas e Gráficos. Bases georreferenciadas para comparação do desempenho socioeconômico dos municípios gaúchos entre 1966 e 2006.

. Perfil Socioeconômico. Disponível em:

<http://www.fee.tche.br/sitefee/pt/content/resumo/index.php>. Acesso em: 15 ago. 2016.

FURTADO. C. O Mito do Desenvolvimento Econômico. Rio de Janeiro: Paz e Terra, 1974 .

PROGRAMA DAS NAÇÕES UNIDAS PARA O DESENVOLVIMENTO - PNUD. Disponível em: <www.pnud.org.br>. Acesso em: 22 ago. 2016.

SANTOS. M. Por uma outra globalização: do pensamento único à consciência universal. São Paulo: Record, 2000.

SANTOS. M.; SILVEIRA, M. L. O Brasil - território e sociedade no início do século XXI. Rio de Janeiro, Record, 2001.

SECRETARIA DA COORDENAÇÃO E PLANEJAMENTO. Atlas Socioeconômico do Rio Grande do Sul. Porto Alegre. Disponível em:

<http://www.atlassocioeconomico.rs.gov.br/indice-de-desenvolvimentosocioeconomico-novo-idese>. Acesso em: 24 ago. 2016.

SEN, A. Entrevista Programa Roda Viva. In: O Melhor do Roda Viva: o mais antigo e respeitado programa de entrevistas da TV. São Paulo: Editora Conex, 2005. p. 203216.

SIEDENBERG. D. R. (coordenador). Dicionário de Desenvolvimento Regional. Santa Cruz do Sul: EDUNISC, 2006. 168 p. 
Tamara Silvana Menuzzi Diverio. Doutora em Desenvolvimento Rural (UFRGS). Bacharel em Ciências Econômicas (UFSM). Docente na Universidade Regional Integrada do Alto Uruguai e das Missões (URI/FW) e do Mestrado Profissional em Desenvolvimento Rural da UNICRUZ.diverio@uri.edu.br

Luiz Gustavo Zuliani da Silva. Mestre em Desenvolvimento Regional (UNISC). Bacharel em Ciências Econômicas (UFSM). Engenheiro Civil (URI). Professor do Departamento de Ciências Sociais e Aplicadas da Universidade Regional Integrada do Alto Uruguai e das Missões - URI - Campus Frederico Westphalen. zuliani@uri.edu.br 